\title{
Applying Depression-Distortion Hypotheses to the Assessment of Peer Victimization in Adolescents
}

\author{
Andres De Los Reyes and Mitchell J. Prinstein \\ Department of Psychology, Yale University
}

\begin{abstract}
This study examined whether adolescents' depressive symptoms and aggressive behavior were associated with discrepancies between self-and peer-reports of peer victimization experiences. A sample of 203 10th-grade adolescents completed self-report measures of victimization and depressive symptoms as well as peer nominations of victimization and aggression. Residual scores were computed as a measure of discordance between peer-and self-reported peer victimization. Adolescents' aggressive behavior was associated with underestimations of peer victimization on self-reported measures, as compared to peer-reports, whereas depressive symptoms were associated with overestimations of peer victimization on self-report, as compared to peer-reports. Different patterns of findings were revealed for different forms of victimization (overt, relational, reputational) and by gender. Findings have implications for studies of adolescent peer victimization using multiple reporters and suggest that adolescents with high levels of depressive symptoms may be vulnerable to misperceptions of their social experiences among peers.
\end{abstract}

Contemporary approaches to the assessment of child and adolescent psychological adjustment routinely involve the collection and integration of data from multiple informants (Frick \& Kamphaus, 2001; Frick, Silverthorn, \& Evans, 1994). Unfortunately, this approach often yields substantial discordance between informants' reports, leading to interpretation problems for both clinicians and investigators (e.g., Achenbach, McConaughy, \& Howell, 1987; Epkins, 1995). Discrepancies among reporters often raise legitimate questions regarding potential informant biases that compromise the integrity of reports and obfuscate findings from clinical evaluations and treatment outcomes. Informant discordance also has significant implications for developmental psychopathology investigations, particularly when differential patterns of associations emerge for different informants. These dilemmas have motivated investigators to study factors that may contribute to reporting biases and discordance among informants.

For instance, numerous investigations have offered evidence in support of a depression-distortion hypothesis (Boyle \& Pickles, 1997a, 1997b; BriggsGowan, Carter, \& Schwab-Stone, 1996; Chi \& Hinshaw, 2002; Chilcoat \& Breslau, 1997; Epkins, 1994; Fergusson, Lynskey, \& Horwood 1993; Naj-

This work was supported, in part, by grants from the National Institute of Mental Health awarded to Andres De Los Reyes (F31-MH67540) and Mitchell J. Prinstein (R01-MH59766).

Requests for reprints should be sent to Mitchell Prinstein, Department of Psychology, Yale University, P.O. Box 208205, New Haven, CT 06520-8205. E-mail: mitch.prinstein@yale.edu man et al., 2000; Richters, 1992), suggesting that external reports of psychological maladjustment may be inflated by an informant's level of depressed mood. The hypothesis has most frequently been examined by comparing mothers' reports of their children's externalizing behavior to the reports of other reliable informants of children's externalizing behavior, such as teachers (e.g., Briggs-Gowan et al., 1996; Chi \& Hinshaw, 2002). Studies using a variety of statistical techniques have offered empirical support for this hypothesis (Boyle \& Pickles, 1997a, 1997b; Chilcoat \& Breslau, 1997; Fergusson et al., 1993; Youngstrom, Izard, \& Ackerman, 1999). Specifically, findings indicate that although depressed mothers do indeed have children who exhibit more severe levels of externalizing behavior than other children, depressed mothers' reports of their children's behavior nevertheless appear to be an overestimate of their children's symptoms when compared to reports from other informants (Youngstrom, Loeber, \& Stouthamer-Loeber, 2000). Given that youth oppositional behavior often occurs in the context of social negotiations with parents (i.e., primarily mothers), these results can be interpreted to suggest that mothers' level of depressed mood may lead to distortions in the interpretation of social interactions as overly negative in valence (Patterson, 1982; Youngstrom et al., 1999). Indeed, the findings are consistent with a large body of research on adult depression regarding social information processing biases influenced by depressed mood (Gotlib \& Hammen, 1992; Ingram, 1984). 
As compared to the study of distortion in maternal reports, prior research rarely has examined whether the depression-distortion hypothesis may help to explain discordance among other informants, or for constructs of social-psychological functioning other than psychological symptoms (Epkins, 1994). In particular, the depression-distortion hypothesis may be especially useful when examining discordance among reporters of peer victimization. The assessment of peer victimization typically relies on peer-reported sociometric measures, such as peer nominations. This approach is widely considered to yield the most reliable and valid estimates of child and adolescent peer experiences, not only because it relies on the most appropriate sources of information regarding peer reputations (i.e., peers), but also because the computations involved in producing sociometric scores produce a summary of multiple informants' (i.e., peer nominators') responses, thus minimizing the effect of any individual informant's potential bias (Bagwell, Coie, Terry, \& Lochman, 2000). Unfortunately, practical constraints often limit clinicians' and investigators' opportunities to collect sociometric data regarding child and adolescent peer victimization (see Zakriski et al., 1999, for a review); thus many rely on self-reported measures of peer victimization (e.g., Austin \& Joseph, 1996; Björkqvist, Ekman, \& Lagerspetz, 1982; Callaghan \& Joseph, 1995; Grills \& Ollendick, 2002; Prinstein, Boergers, \& Vernberg, 2001; Vernberg, 1990).

Yet findings suggest that self- and peer-reports of victimization may differ in at least three ways. First, as with many other constructs of social-psychological functioning, findings have revealed only low to moderate correspondence between peer- and self-reported measures of peer victimization in childhood and adolescence (e.g., Graham \& Juvonen, 1998; Hawker, 1997; Juvonen, Nishina, \& Graham, 2001; Ladd \& Kochenderfer-Ladd, 2002; Österman et al., 1994; Perry, Kusel, \& Perry, 1988), and little is known about factors that may contribute to this discordance.

Second, recent work has revealed substantially different prevalence rates of victimization in youth, depending on the use of either self- or peer-reported instruments. For example, Ladd and Kochenderfer-Ladd (2002) found that estimates of the prevalence of victimization in children were significantly higher using self-reports as compared to peer reports. The accurate identification of child and adolescent "victims" has considerable implications for the development of prevention programs and the study of youth who are at greatest risk for subsequent distress.

Third, the results of recent investigations suggest that different patterns of associations emerge between self- and peer-reports of victimization and psychological adjustment. For instance, a meta-analysis of concurrent associations between peer victimization and psychosocial maladjustment involving studies con- ducted over the past two decades revealed notable differences in the magnitude of effects based on the informant (Hawker \& Boulton, 2000). Investigations of the concurrent association between peer victimization and depression using exclusively self-reported measures revealed a medium to large effect size ( $r$ s reaching .81; mean $r=.45$; mean shared variance $=20.3 \%$ ); however, studies examining the association between peer-reported peer victimization and self-reported depressive symptoms approached only a small to medium effect size ( $r$ s reaching .36; mean $r=.29$; mean shared variance $=8.4 \%$; see Cohen, 1988). Overall, the findings in this area strongly suggest that factors such as method variance or informant biases may lead to substantially different information yielded from selfand peer-reported assessments of peer victimization.

The potential application of depression-distortion hypotheses to the assessment of peer victimization experiences is especially relevant in light of recent work regarding multiple forms of peer aggression and victimization. For decades, research exclusively examined overt or physical forms of peer aggression (e.g., hitting, kicking, teasing); however, recent work has identified forms of indirect aggression that may be more covert or less confrontational in nature and thus perhaps more prone to misperception and distortion by victims. For instance, relational aggression is one form of indirect aggression that uses a relationship (i.e., the friendship) as a weapon to harm others (e.g., by withdrawing friendship support or ignoring; Crick \& Grotpeter, 1995; Galen \& Underwood, 1997). Other forms of indirect aggression (i.e., reputational) involve attempts to damage a victim's social reputation within the peer group hierarchy (e.g., by telling gossip or rumors, enlisting others to dislike a peer; Hart et al., 2001; Prinstein \& Cillessen, 2003; Xie, Swift, Cairns, $\&$ Cairns, 2002).

Indirect forms of aggression are especially prominent during adolescence, when sanctions for overt forms of aggression become more severe (Prinstein et al., 2001; Underwood, Galen, \& Paquette, 2001). Thus, it was anticipated that adolescents may be particularly prone toward distortions in perceptions of relational and reputational victimization, given the ambiguous nature of these forms of victimization and their frequency at this developmental stage. This important developmental period is also associated with dramatic increases in the prevalence of depressive symptoms, particularly among girls (Nolen-Hoeksema \& Girgus, 1994). Therefore, it was further hypothesized that the association between depressive symptoms and distortions in adolescents' perceptions of victimization would be moderated by gender, with greater discordance between self- and peer-reports among girls as compared to boys.

This study was designed to examine depression as a possible correlate of discrepancies between adoles- 
cents' self- and peer-reported peer victimization experiences. Prior research has suggested that children and adolescents may exhibit significant distortions in their perceptions of related areas of social and peer experiences. However, most of this prior work has examined youth aggression as a factor that may contribute to distortions. For instance, findings have suggested that when compared with peer-reports, aggressive children overestimate their levels of peer acceptance and social competence and underestimate their level of peer rejection (Boivin, Poulin, \& Vitaro, 1994; Hughes, Cavell, \& Grossman, 1997; Rudolph \& Clark, 2001; Zakriski \& Coie, 1996).

In contrast, research suggests that depression may be associated with underestimations of competence and peer acceptance (Cillessen \& Bellmore, 1999; Rudolph \& Clark, 2001). For instance, Rudolph and Clark (2001) revealed that depressed-unpopular youth reported more negative perceptions of self- and peer relationships than nondepressed-unpopular youth, despite similar levels of negative experiences in the peer domain. Similarly, Brendgen, Vitaro, Turgeon, and Poulin (2002) found that aggressive children overestimated their social acceptance, relative to peer-reports, and depressed children underestimated both their social acceptance and friendship quality, relative to peer and friend's reports, respectively. The study of youth distortions in their perceptions of peer victimization experiences is especially important to build on these prior results. As compared to self-perceptions of social competence and peer status more generally, perceptions of peer victimization experiences are significantly associated with retaliatory aggressive behavior, exacerbations of depression, and suicidal ideation (Prinstein, 2003; Rigby \& Slee, 1999).

This study extended the existing literature on cognitive distortions and the depression-distortion hypothesis by examining aggression and depression as correlates of discrepancies between self- and peer-reports of peer victimization experiences. Discrepancies between self- and peer-reports of peer victimization were examined using techniques that are appropriate when measures administered to different informants differ in item content, metric, or variability (e.g., Treutler \& Epkins, 2003). Specifically, residual scores were computed as an index of discrepancies between self- and peer-reported measures of overt, relational, and reputational forms of victimization (e.g., see Brendgen et al., 2002; Chi \& Hinshaw, 2002; Cole, Martin, Peeke, Seroczynski, \& Hoffman, 1998; McGrath \& Repetti, 2002, for examples of this approach). Associations among these residual scores (i.e., discrepancies), adolescents' aggression, and depressive symptoms were then examined. It should be noted that other approaches for measuring informant discrepancies (or analysis of change) were also considered (e.g., a difference score approach). However, these approaches may be more conceptually and empirically appropriate when identical measures are administered to both groups of informants, when neither informant measure is generally regarded as an optimal approach (i.e., neither is considered a "gold standard"), or when one of the informant approaches yields a measure that is strongly correlated with the source of distortion (Edwards, 1994; Rogosa, Brandt, \& Zimowski, 1982; Treutler \& Epkins, 2003).

Consistent with prior research (Rudolph \& Clark, 2001), depressive symptoms and aggression were measured using methods and informants that are widely considered to offer maximal validity (e.g., Edelbrock, 1994; Edelbrock, Costello, Dulcan, Kalas, \& Conover, 1985). Specifically, depressive symptoms were assessed using a self-reported instrument and aggression was assessed using peer-reported nominations. It was anticipated that when compared to peer-reported victimization, aggression would be associated with adolescents' underestimates of peer victimization, whereas depressive symptoms would be associated with adolescents' overestimates of peer victimization. It was also hypothesized that this pattern of results would be especially prominent for indirect forms of victimization, including relational and reputational forms, and among girls.

\section{Method}

\section{Participants}

Participants included 203 tenth-grade students (81 boys, 40\%; 122 girls, 60\%) in a New England high school. All adolescents were between 15 and 17 years old $(M=16.31, S D=.50)$. The ethnic distribution of the sample was $76.9 \%$ White, $9.5 \%$ African American, $4.1 \%$ Hispanic, and $9.5 \%$ other/mixed ethnicity. The school was located in a city of fairly homogeneous socioeconomic status (per capita income $=\$ 25,175$; Connecticut State Department of Education, 2000). According to school records, approximately $22.3 \%$ of students were eligible for free or reduced-price lunch.

\section{Procedures}

All 10th-grade students were recruited for participation, with the exception of students in self-contained special education classes. Consent forms were returned by $70 \%$ of families $(n=255)$; of these, $92 \%$ of parents gave consent for their child's participation ( $n=$ 235). Data were missing for 6 students who were absent on the days of testing and were unable to provide assent, as well as for 26 other students who did not complete the measures of interest in this study. Analyses comparing consented adolescents with and without complete data revealed no significant differences on any primary variables included in this study. 
Sociometric assessment. Peer nominations of peer victimization and aggression were obtained using an expert sociometric procedure (Cairns, Gariépy, \& Kindermann, 1991; Cairns, Xie, \& Leung, 1998; Clasen \& Brown, 1985; Prinstein, in press; Prinstein \& Cillessen, 2003). Specifically, a subsample of adolescents nominated by their teachers as social experts $(n=26$; approximately $10 \%$ of sample) participated in individual interviews regarding victims and perpetrators of peer aggression. Using rosters of all grade-mates, experts were asked to provide unlimited nominations for items of overt aggression ("Who says mean things, threatens, or physically hurts others-for instance, hitting, kicking or pushing others, teasing or calling names?"), relational aggression ("Who uses their friendships as a way of being mean to others-for instance, by telling people that they will not be their friend, excluding someone from their group of friends, or giving someone the "silent treatment'?"), and reputational aggression ("Who does things to damage someone's social reputationfor instance, telling rumors about them, gossiping, and saying mean things behind their back?"). A similar set of items was used to examine overt victimization ("Who gets threatened or physically hurt by others, or has mean things said about them?"), relational victimization ("Who gets excluded from a group of friends, or is given the 'silent treatment?"), and reputational victimization ("Who gets their social reputation damaged by others [e.g., gets gossiped about or has mean things said about them behind their back]?"). A total number of nominations received by each adolescent was computed and standardized for each item of peer aggression and victimization.

Evidence from several studies indicates that the use of a subsample of experts yields reliable and valid estimates of peer reputations, particularly when using an unlimited nomination procedure. For example, Terry and colleagues revealed that measures of peer status derived from responses made by $10 \%$ of participants yielded scores that were moderately to strongly correlated with scores from the full sample ( $r=.61$; Angold et al., 1990; Terry, Coie, Lochman, \& Cillessen, 1998). Similarly, Prinstein (in press) revealed moderate to strong correlations between scores derived from expert nominators and the full sample for social preference, $r=$ $.62, p<.001$, and peer-perceived popularity, $r=.87, p<$ .001 . Data from the same study indicate comparable associations between nominations made by experts and the full sample for several reputation measures, including academic achievement, $r=.79, p<.001$, physical attractiveness, $r=.84, p<.001$, and overt aggression, $r=$ $.67, p<.001$.

\section{Self-Reported Measures}

Depressive symptoms. The Children's Depression Inventory (Kovacs, 1981) is a 27-item measure designed to assess cognitive and behavioral depressive symptoms in children and adolescents. For each item, respondents select from one of three statements, scored 0 through 2 , which best described their level of depressive symptoms in the previous 2 weeks. One item on suicidal ideation was omitted in response to concerns from the Institutional Review Board, and a summed score was computed across the remaining 26 items, with higher scores reflecting more depressive symptoms. Good psychometric properties have been reported for the Children's Depression Inventory as a reliable and valid index of depressive symptoms (Saylor, Finch, Spirito, \& Bennett, 1984); it can be used with youth between the ages of 7 and 18 years of age (Kazdin, 1990). In our sample, internal consistency was high, $\alpha=.87$.

Self-reported victimization. The Revised Peer Experiences Questionnaire (RPEQ; Prinstein et al., 2001) was administered to obtain adolescents' self-reported levels of victimization. The RPEQ is a revision of a measure originally developed by Vernberg, Jacobs, and Hershberger (1999) to assess youths' aggression and victimization among peers in the school context. Although the original version assessed mostly overt forms of aggression and victimization, the RPEQ includes additional items adapted from prior instruments (e.g., Lopez, 1998) to assess indirect forms of aggression and victimization (i.e., relational, reputational) as well as the youths' engagement and receipt of prosocial behavior among peers. Specifically, the RPEQ includes two sets of items, presented in counterbalanced order, to assess aggressive (and prosocial) behavior directed toward the teen (i.e., Victim version: 18 items, e.g., "A teen hit, kicked, or pushed me in a mean way") and teens' own aggressive (and prosocial) behavior toward peers (i.e., Bully version: 18 items, e.g., "I hit, kicked, or pushed another teen in a mean way"). Factor analyses in this sample, using a principal components extraction method and oblique rotation (i.e., Oblimin), revealed a stable and virtually identical factor structure for 14 items on both the Bully and Victim versions of this instrument (see pattern matrix in Table 1), yielding four subscales on each version with eigenvalues greater than 1.0 , or a total of eight subscales: Overt Aggression ( $\alpha=.83$; three items), Overt Victimization ( $\alpha=.78$; three items), Relational Aggression ( $\alpha$ $=.68$; three items), Relational Victimization $(\alpha=.84$; three items); Reputational Aggression $(\alpha=.76$; three items), Reputational Victimization $(\alpha=.83$; three items); Prosocial Behavior Toward Others $(\alpha=.79$; five items), and Receipt of Prosocial Behavior ( $\alpha=.82$; five items; see Table 1). Because oblique rotation was used, factors were allowed to correlate with each other. Results from only the Victim version of the RPEQ were included for this study.

The initial version of the Peer Experiences Questionnaire has demonstrated good validity in related studies with children and adolescents. Children's self- 


\begin{tabular}{|c|c|c|c|c|c|c|c|c|}
\hline \multirow[b]{2}{*}{ Subscale and Item ${ }^{a}$} & \multicolumn{4}{|c|}{ Bully Version } & \multicolumn{4}{|c|}{ Victim Version } \\
\hline & Factor I & Factor II & Factor III & Factor IV & Factor I & Factor II & Factor III & Factor IV \\
\hline \multicolumn{9}{|l|}{ Overt } \\
\hline $\begin{array}{c}\text { A teen chased me like he or she } \\
\text { was really trying to hurt me }\end{array}$ & .84 & .10 & -.13 & -.05 & .81 & .08 & .04 & -.03 \\
\hline $\begin{array}{l}\text { A teen threatened to hurt or beat } \\
\text { me up }\end{array}$ & $\underline{.89}$ & -.13 & .05 & .05 & .63 & -.03 & .25 & .06 \\
\hline $\begin{array}{l}\text { A teen hit, kicked, or pushed me } \\
\text { in a mean way }\end{array}$ & .85 & .07 & .06 & -.01 & .90 & -.02 & -.01 & -.04 \\
\hline \multicolumn{9}{|l|}{ Relational } \\
\hline $\begin{array}{l}\text { Some teens left me out of an } \\
\text { activity or conversation that I } \\
\text { really wanted to be included in }\end{array}$ & .12 & .72 & .02 & .06 & .03 & .84 & -.02 & .02 \\
\hline $\begin{array}{l}\text { A teen did not invite me to a party } \\
\text { or other social event even } \\
\text { though they knew that I wanted } \\
\text { to go }\end{array}$ & -.04 & .71 & .13 & -.04 & .03 & .82 & .02 & -.04 \\
\hline $\begin{array}{l}\text { A teen left me out of what they } \\
\text { were doing }\end{array}$ & .00 & .76 & .07 & .00 & -.08 & $\underline{.90}$ & .09 & .02 \\
\hline \multicolumn{9}{|l|}{ Reputational } \\
\hline $\begin{array}{l}\text { A teen tried to damage my social } \\
\text { reputation by spreading rumors } \\
\text { about me }\end{array}$ & -.09 & .06 & .84 & .00 & .13 & -.03 & .78 & -.01 \\
\hline $\begin{array}{l}\text { Another teen gossiped about me } \\
\text { so that others would not like me }\end{array}$ & .04 & .14 & .79 & .05 & -.08 & .05 & .92 & -.01 \\
\hline $\begin{array}{l}\text { Another teen said mean things } \\
\text { about me so that people would } \\
\text { think that I was a loser }\end{array}$ & .23 & .21 & .57 & .02 & .22 & .19 &.$\underline{.70}$ & .02 \\
\hline \multicolumn{9}{|l|}{ Prosocial } \\
\hline $\begin{array}{l}\text { Another teen helped me when I } \\
\text { was having a problem }\end{array}$ & -.09 & .23 & -.12 & .73 & -.23 & -.02 & .05 & .84 \\
\hline $\begin{array}{l}\text { Another teen was nice and } \\
\text { friendly to me when I needed } \\
\text { help }\end{array}$ & -.05 & .06 & -.30 & .73 & -.21 & .02 & .00 & .79 \\
\hline $\begin{array}{l}\text { Another teen stuck up for me } \\
\text { when I was being picked on or } \\
\text { excluded }\end{array}$ & .10 & .04 & .05 & .76 & .02 & -.13 & .21 & .74 \\
\hline $\begin{array}{l}\text { A teen helped me join into a } \\
\text { group or conversation }\end{array}$ & -.03 & -.13 & .23 & .74 & .16 & .17 & -.15 & .70 \\
\hline $\begin{array}{l}\text { A teen spent time with me when I } \\
\text { had no one else to hang out } \\
\text { with }\end{array}$ & .05 & -.18 & .16 & .72 & .21 & -.03 & -.10 & .73 \\
\hline Eigenvalues & 1.57 & 1.07 & 3.69 & 2.71 & 3.78 & 1.85 & 1.15 & 2.90 \\
\hline$\%$ Variance Explained & 11.21 & 7.64 & 26.34 & 19.37 & 27.01 & 13.22 & 8.19 & 20.72 \\
\hline
\end{tabular}

Note: Principal component factor loadings $>.40$ (pattern matrix) using oblique rotation (i.e., Oblimin) are underlined.

aWording for the Victim version is listed in this table. For the Bully version, pronouns were reversed (e.g., "I hit, kicked, or pushed a teen in a mean way"; "I threatened to hurt or beat up another teen," and so on).

reported total victimization scores on the Peer Experiences Questionnaire was significantly correlated with peer-reported victimization, defined broadly ( $r$ s between .34 and $.40, p<.001)$. Test-retest reliability over a 6-month interval has ranged from .48 to .52 . Significant correlations were also revealed between self-reported victimization and parent-reported victimization ( $r$ s between .36 and $.39, p<.001)$ in two separate child samples (Vernberg, Fonagy, \& Twemlow, 2000). Similar support for the psychometric properties of the RPEQ has been reported (Prinstein et al., 2001). Internal consistencies for the subscales of the RPEQ range from .76 to .80 , and the measure is significantly, mod- erately correlated with other indexes of social-psychological difficulties (i.e., low perceived social acceptance, loneliness, depressive symptoms), consistent with prior research.

\section{Results}

Means and standard deviations of measures of selfand peer-reported victimization, depressive symptoms, and aggression are presented in Table 2. Higher levels of both self- and peer-reported overt victimization were revealed for boys as compared to girls. In con- 
Table 2. Means and Standard Deviations of Measures of Victimization, Aggression, and Depressive Symptoms

\begin{tabular}{|c|c|c|c|c|c|c|c|c|}
\hline \multirow[b]{2}{*}{ Measures } & \multicolumn{2}{|c|}{ Total $(N=203)$} & \multicolumn{2}{|c|}{ Boys $(n=81)$} & \multicolumn{2}{|c|}{ Girls $(n=122)$} & \multicolumn{2}{|c|}{ Gender Differences } \\
\hline & $M$ & $S D$ & $M$ & $S D$ & $M$ & $S D$ & $d f$ & $t$ \\
\hline \multicolumn{9}{|l|}{ Self-reported victimization } \\
\hline Overt & 1.46 & .63 & 1.61 & .70 & 1.35 & .55 & $141.75^{\mathrm{a}}$ & $2.83 * *$ \\
\hline Relational & 2.03 & .76 & 2.02 & .84 & 2.03 & .71 & 201 & -.10 \\
\hline Reputational & 1.77 & .81 & 1.74 & .84 & 1.80 & .79 & 201 & -.47 \\
\hline \multicolumn{9}{|l|}{ Peer-reported victimization } \\
\hline Overt & .11 & 1.07 & .33 & 1.28 & -.04 & .88 & $129.84^{\mathrm{a}}$ & $2.31 *$ \\
\hline Relational & .16 & 1.08 & .20 & 1.21 & .14 & .99 & 201 & .43 \\
\hline Reputational & .13 & 1.10 & -.14 & .80 & .30 & 1.23 & $200.94^{\mathrm{a}}$ & $-3.12 * *$ \\
\hline \multicolumn{9}{|l|}{ Peer-reported aggression } \\
\hline Overt & -.15 & .71 & -.20 & .66 & -.11 & .74 & 201 & -.96 \\
\hline Relational & .03 & 1.07 & -.30 & .51 & .23 & 1.27 & $170.67^{\mathrm{a}}$ & $-4.13 * * *$ \\
\hline Reputational & .02 & 1.09 & -.34 & .36 & .26 & 1.32 & $146.47^{a}$ & $-4.75^{* * *}$ \\
\hline Depressive symptoms & 8.95 & 6.30 & 7.86 & 5.80 & 9.66 & 6.53 & 201 & $-2.01^{*}$ \\
\hline
\end{tabular}

${ }^{\mathrm{a} E q u a l}$ variances not assumed.

$* p<.05 . * * p<.01 . * * * p<.001$.

Table 3. Pearson Correlations Among Self-Reports and Peer Reports of Victimization

\begin{tabular}{|c|c|c|c|c|c|}
\hline & \multicolumn{2}{|c|}{ Self-Reported Victimization } & \multicolumn{3}{|c|}{ Peer-Reported Victimization } \\
\hline & Relational & Reputational & Overt & Relational & Reputational \\
\hline \multicolumn{6}{|c|}{ Self-reported victimization } \\
\hline Overt & $.26 * * *$ & $.51 * * *$ & $.17 *$ & $.15^{*}$ & .04 \\
\hline Relational & & $.32 * * *$ & $.22 * * *$ & $.21 * *$ & -.02 \\
\hline Reputational & & & $.24 * * *$ & $.21 * *$ & $.27 * * *$ \\
\hline \multicolumn{6}{|c|}{ Peer-reported victimization } \\
\hline Overt & & & & $.73 * * *$ & $.48 * * *$ \\
\hline Relational & & & & & $.50 * * *$ \\
\hline
\end{tabular}

$* p<.05 . * * p<.01 . * * * p<.001$.

trast, greater levels of peer-reported reputational victimization, reputational aggression, and relational victimization were revealed for girls (see Table 2). Results from paired $t$ tests revealed that adolescents reported greater levels of indirect forms of victimization (i.e., relational and reputational) on the RPEQ as compared to reported levels of overt victimization, $t \mathrm{~s}(202)=$ $-9.58,6.24, p s<.001$, respectively. Correlations between self- and peer-reported measures of victimization were also conducted to examine bivariate associations. As anticipated, correspondence between reporters was significant but low (see Table 3 ).

To examine discrepancies between self- and peer-reports of victimization, residual scores were created using regression procedures, in which self-reported victimization was the dependent variable, the corresponding form of peer-reported victimization was the independent variable, and the resulting standardized residual was saved as a new variable. Thus, residual scores captured the variance of the self-reports of victimization not accounted for by the variance of the peer-reports of victimization. This procedure yielded three measures of self- vs. peer-reported discrepancies of victimization: (a) an overt victimization residual score, (b) a relational victimization residual score, and (c) a reputational victimization residual score. Because the residuals each had a mean of zero, a positive residual score reflected adolescents' overestimation of victimization on self-report as compared to peer-reports, and a negative residual score reflected adolescents' underestimation of victimization on self-report as compared to peer-reports.

Hierarchical multiple regressions were conducted to examine whether adolescents' depressive symptoms and aggression were related to self-peer discrepancies on reports of victimization. Three models were examined using the overt victimization residual score, relational victimization residual score, and reputational victimization residual score as dependent variables in three separate hierarchical regression equations. For each model, depressive symptoms and the corresponding form of aggression (e.g., relational aggression was an independent variable when the relational victimization residual score was the dependent variable) were entered simultaneously to examine shared and unique associations with self-peer discrepancies on reports of victimization. To examine potential gender interactions, gender was entered on a second step, and two interaction terms (Gender $\times$ Depressive Symptoms; Gender $\times$ Aggression) were entered on a third step of each model. 
In the presence of a significant interaction effect, Holmbeck's (2002) most recent guidelines for post hoc probing of significant moderator effects were used. This included (a) recomputation of a "reduced" regression model, including only significant predictors to eliminate potential errors in parameter estimation or errors in partialling of unique effects due to multicollinearity and the possibility that suppressor effects were responsible for significant interaction terms; (b) computation of slope estimates using centered variables (thus, further reducing multicollinearity); and (c) examining the statistical significance of these slopes for each gender (i.e., the moderator variable). All results are presented in Table 4.

\section{Overt Victimization}

A significant model was revealed for overt victimization. Results revealed that greater levels of adolescents' depressive symptoms were significantly associated with adolescents' overestimations of overt victimization on self-reports relative to peer-reports (see Table 4). However, this result was qualified by a significant gender interaction. Results of post hoc probing revealed a positive, significant slope between depressive symptoms and overt residual scores for boys. This indicated that greater levels of adolescent boys' depressive symptoms were significantly associated with adolescents' overestimations of self-reported overt victimization relative to peer-reported overt victimization, $\beta=.47 ; t=4.10, p<.001$. However, no significant slope was revealed for girls, $\beta=.07 ; t=.86, n s$.

\section{Relational Victimization}

A significant model was revealed for relational victimization. Results revealed that greater levels of adolescents' depressive symptoms and lower levels of adolescents' relational aggression were significantly associated with adolescents' overestimations of relational victimization on self-reports relative to peer-re- ports (see Table 4). No significant main or interaction effects for gender were found.

\section{Reputational Victimization}

A significant model was revealed for reputational victimization. Results revealed that greater levels of adolescents' depressive symptoms were significantly associated with adolescents' overestimations of reputational victimization on self-reports relative to peer-reports (see Table 4). No significant main or interaction effects for gender were found.

\section{Discussion}

Investigations of peer victimization have grown in number dramatically over the past decade (Hawker \& Boulton, 2000). This trend has been accompanied by an expanding number of methodological approaches to studying youth victimization; however, recent research has revealed that each of these approaches (i.e., selfand peer report) yields notably different results regarding the prevalence and correlates of victimization (Ladd \& Kochenderfer-Ladd, 2002). Findings from this preliminary study revealed two factors that may be associated with discrepancies between self- and peerreported measures of peer victimization.

Results indicated that adolescents' depressive symptoms were associated with overestimations of peer victimization on self-reported, as compared to peer-reported, measures, whereas adolescents' aggression was associated with underestimations. These results are consistent with several past studies (Brendgen et al., 2002; Cillessen \& Bellmore, 1999; Rudolph \& Clark, 2001) and with social information processing theories. Depressed individuals are more likely than nondepressed individuals to encode interpersonal cues as negative in valence and to perceive a greater number of stressful events, particularly in the interpersonal domain (Ingram, 1984; Rudolph, Hammen, \& Burge,

Table 4. Hierarchical Regression Analyses Examining Associations Among Adolescents' Depressive Symptoms, Aggression and Self-Peer Discrepancies (i.e., Residual Scores) of Victimization

\begin{tabular}{|c|c|c|c|c|c|c|}
\hline \multirow[b]{2}{*}{ Variable } & \multicolumn{2}{|c|}{ Overt Residual Score } & \multicolumn{2}{|c|}{$\begin{array}{c}\text { Relational Residual } \\
\text { Score }\end{array}$} & \multicolumn{2}{|c|}{$\begin{array}{c}\text { Reputational Residual } \\
\text { Score }\end{array}$} \\
\hline & $\Delta \mathbf{R}^{2}$ & $\beta$ & $\Delta \mathbf{R}^{2}$ & $\beta$ & $\Delta \mathbf{R}^{2}$ & $\beta$ \\
\hline Step 1 & $.03 *$ & & $.13 * * *$ & & $.05 * *$ & \\
\hline Depressive symptoms & & $.18^{*}$ & & $.25 * * *$ & & $.22 * *$ \\
\hline Corresponding form of aggression & & .02 & & $-.28 * * *$ & & -.04 \\
\hline Step 2 & $.04 * *$ & & .00 & & .00 & \\
\hline Gender & & $-.21 * *$ & & .05 & & -.04 \\
\hline Step 3 & $.04 *$ & & .01 & & .01 & \\
\hline Depressive Symptoms $\times$ Gender & & $-.44 * *$ & & -.12 & & -.14 \\
\hline Aggression $\times$ Gender & & -.04 & & .27 & & -.17 \\
\hline Total $F(5,197)$ & 4.97 & & 6.29 & & 2.25 & \\
\hline
\end{tabular}

$* p<.05 . * * p<.01 . * * * p<.001$. 
1994), whereas aggressive youth may lack the skills necessary to appropriately encode cues that reflect their difficulty in the peer domain (Bierman \& Wargo, 1995; Rudolph \& Clark, 2001). Application of these ideas to the study of peer victimization is particularly important; youths' misperceptions of victimization experiences may have severe potential consequences, including retaliatory aggressive behavior, school avoidance, depression, and suicidality (Juvonen et al., 2001).

This extension of the depression-distortion hypothesis to the study of peer victimization also offers an important contribution to ongoing studies of cognitive and interpersonal models of adolescent depression that incorporate peer experiences as relevant predictors (e.g., Prinstein, Cheah, \& Schweder, 2003; Rudolph \& Clark, 2001). Several studies have demonstrated that depression is associated with adolescents' cue interpretations of peer experiences (e.g., Panak \& Garber, 1992; Prinstein et al., 2003). Results from this study apply to adolescents' encoding of peer experiences. Thus, depressed adolescents may not only be interpreting actual stressful experiences in a manner that exacerbates depressive symptoms, but also may exhibit an exaggerated tendency to perceive stressful events from ambiguous peer experiences (Prinstein et al., 2003). Future research should continue to examine the manner in which the mutually reinforcing associations between cue encoding and cue interpretations of peer experiences may contribute to a downward spiral of depressive symptoms during adolescence and how this model may differ by gender.

Indeed, results revealed some important gender differences that are consistent with past research in the peer victimization literature. Specifically, findings indicated that depression was significantly associated with self-peer discrepancies on measures of overt victimization for boys only. This finding is generally consistent with results revealing boys' greater tendencies to utilize overt aggression as compared to girls. In contrast, depression was a significant predictor of self-peer discrepancies for both forms of indirect victimization (i.e., relational and reputational forms) among boys and girls. Research has demonstrated that indirect forms of victimization are especially relevant in adolescence, and several studies have revealed no (or only small) gender differences in the frequency of indirect victimization at this developmental stage (e.g., Prinstein, Boergers, Spirito, Little, \& Grapentine, 2000). Thus, results suggest that adolescents may be most likely to exhibit depression-related distortions in their perceptions of peer victimization experiences for those forms of victimization that are most prevalent at their developmental level.

Of course, the findings in this study may also be interpreted to suggest that peers', rather than adolescents', perceptions of peer victimization experiences are distorted (Epkins, 1994). The peer sociometric procedure yields a summary score for each adolescent based on the composite of multiple peers' nominations, thus greatly reducing the effect of a single adolescents' distortion on peer victimization scores. However, there are several reasons to suspect that peers nevertheless may be inaccurate in their reports of adolescents' peer victimization. For instance, peers rarely have access to all peer victimization encounters experienced by individual adolescents, particularly indirect forms of victimization that occur within the friendship clique or in somewhat subtle ways (e.g., exclusion). Peers may also be especially prone toward bias when reporting victimization in adolescence. As compared to the classroom sociometric procedure typically used in childhood (i.e., peer nominators spend considerable time in a single classroom with each nominee), adolescent peer nominations are conducted using all grade-mates, and individual nominators may have little direct contact with nominees.

From this perspective, findings from this study could be interpreted to suggest that as compared to adolescents' own report, peers are likely to underreport peer victimization experiences for those adolescents who exhibit high levels of depressive symptoms and overreport victimization experiences for adolescents who exhibit high levels of aggressive symptoms. However, this interpretation would be only partially supported by past research. Youth with high levels of depressed affect, based on either self- or peer-reports, are typically nominated by peers as rejected and victimized (e.g., Cole \& Carpentieri, 1990; Panak \& Garber, 1992). Moreover, reputations of passivity and sad affect are strong determinants of peer victimization (Perry, Hodges, \& Egan, 2001). Thus, it seems somewhat unlikely that peers would exhibit an underestimation bias regarding depressed adolescents' level of victimization. In contrast, past research has demonstrated strong reputations of rejection and victimization for some youth who are aggressive (Olweus, 1978; Schwartz, Dodge, Pettit, \& Bates, 1997). Thus, it is possible that adolescents may be overestimating the levels of victimization experienced by adolescents who are perceived as aggressive. In sum, the findings from this study highlight factors that appear to be associated with self-peer discrepancies in reports of peer victimization but cannot be used to determine the absolute accuracy of reports from either informant.

This point is also relevant for considering possible limitations in the residual score approach for measuring informant discrepancies. One appropriate use of the residual score approach for analyzing informant discrepancies pertains to the comparison of an informant's report to an established "gold standard." This is because the residual score approach examines variability in one informant's report (i.e., self-report) that is not accounted for by the "gold standard" assessment 
(i.e., peer-report) and may be associated with potential sources of bias (e.g., aggression or depression). Therefore, it should be noted that if this assumption is erroneous (i.e., peer-report should not be considered a gold standard), then this approach would be called into question and the residual score approach would potentially lead to overestimations of distortion. Thus, results from this study should be interpreted cautiously and will require replication in subsequent work. Indeed, there is no current consensus regarding an analytic approach for examining informant discrepancies that is appropriate for all types of datasets (cf. Cohen \& Cohen, 1983; Colvin, Block, \& Funder, 1996; Edwards, 1994; Rogosa et al., 1982; Zuckerman, Gagne, Nafshi, Knee, \& Kieffer, 2002).

Although the findings from this study call into question the sole use of self-reports to measure peer victimization in adolescents, the results from self-report measures of peer victimization should not be regarded as necessarily faulty or lacking in utility. Past studies have demonstrated that youths' perceptions of peer experiences may be as important for internalizing adjustment, or even more so, than actual peer experiences (Juvonen et al., 2001; Ladd \& Kochenderfer-Ladd, 2002; Panak \& Garber, 1992). As with many other constructs of social-psychological functioning in the clinical child literature, it is important to note that no single informant of peer victimization can be regarded as an objective ideal standard. Rather, each reporter may have access to unique contexts in which to observe an individual's behavior and may be influenced by a unique set of biases that can affect reports (Achenbach et al., 1987). Assessment approaches involving multiple informants of peer victimization should be adopted in future work (Juvonen et al., 2001; Ladd \& Kochenderfer-Ladd, 2002).

Overall, this preliminary study addresses several important questions regarding methodological approaches to the assessment of peer victimization. Findings from this initial investigation should be replicated in subsequent investigations that address some of the potential limitations of this study. For instance, continued work is needed to examine possible developmental differences in the correlates of self-peer discrepancies in reports of peer victimization. Exploration of these questions in a sample of younger children would likely allow for the use of a standard classroom-based peer nomination procedure to obtain a peer-reported assessment of victimization. We considered the possibility that our reliance on a limited number of teacher-selected nominators for peer measures of aggression and victimization in this adolescent sample may have contributed to discrepancies between self- and peer-reports or may have led to a unique set of peer biases. However, findings revealed similar levels of self-peer discordance in this study as compared to other studies using a traditional classroom-based procedure. More- over, findings from several recent studies have offered good support for the validity of the expert peer nomination procedure among adolescents (Prinstein, in press; Prinstein \& Cillessen, 2003). Nevertheless, this is an important area for further study.

More work is also needed to examine discordance between peer- and self-reports of the different forms of victimization. Although the self-report measure used in this study supported the distinction between overt and indirect forms of victimization in factor analyses, through differential patterns of associations when examining study hypotheses, and in past research (e.g., Prinstein et al., 2000), correlations between the self-report subscales and peer-reported measures of the same constructs did not offer good evidence for discriminant validity in this particular sample. Indeed, the low level of correspondence between self- and peer-reported measures of the same construct is central to the hypotheses of this article and should be examined carefully in any research using self-reported instruments designed to assess different forms of victimization.

The findings from this preliminary investigation offer unique data regarding factors that may be associated with discrepancies between peer- and self-reports of peer victimization. Findings have significant implications for future studies of peer victimization relying on a single informant and raise important questions regarding the potential bidirectionality of associations revealed between reports of victimization and psychological adjustment relying on the same source. Findings also suggest that the depression-distortion hypothesis may prove useful in understanding discrepancies between adolescents' and their peers' reports and possibly in the assessment of a broader array of social-psychological constructs.

\section{References}

Achenbach, T. M., McConaughy, S. H., \& Howell, C. T. (1987). Child/adolescent behavioral and emotional problems: Implications of cross-informant correlations for situational specificity. Psychological Bulletin, 101, 213-232.

Angold, A., Coie, J. D., Burns, B. J., Terry, R., Costello, E. J., Lochman, J., et al. (1990). Methods for developmental studies of conduct problems: Assessments of service use and peer ratings of social status and behavior. Grant application.

Austin, S., \& Joseph, S. (1996). Assessment of bully/victim problems in 8- to 11-year-olds. British Journal of Educational Psychology, 66, 447-456.

Bagwell, C. L., Coie, J. D., Terry, R. A., \& Lochman, J. E. (2000). Peer clique participation and social status in preadolescence. Merrill-Palmer Quarterly, 46, 280-305.

Bierman, K. L., \& Wargo, J. B. (1995). Predicting the longitudinal course associated with aggressive rejected, aggressive (non-rejected), and rejected (non-aggressive) status. Development and Psychopathology, 7, 669-682.

Björkqvist, K. Ekman, K., \& Lagerspetz, K. (1982). Bullies and victims: Their ego picture, ideal ego picture and normative ego picture. Scandinavian Journal of Psychology, 23, 307-313. 
Boivin, M., Poulin, F., \& Vitaro, F. (1994). Depressed mood and peer rejection in childhood. Development and Psychopathology, 6, 483-498.

Boyle, M. H., \& Pickles, A. (1997a). Influence of maternal depressive symptoms on ratings of childhood behavior. Journal of Abnormal Child Psychology, 25, 399-412.

Boyle, M. H., \& Pickles, A. (1997b). Maternal depressive symptoms and ratings of emotional disorder symptoms in children and adolescents. Journal of Child Psychology and Psychiatry, 38, 981-992.

Brendgen, M., Vitaro, F., Turgeon, L., \& Poulin, F. (2002). Assessing aggressive and depressed children's social relations with classmates and friends: A matter of perspective. Journal of Abnormal Child Psychology, 30, 609-624.

Briggs-Gowan, M. J., Carter, A. S., \& Schwab-Stone, M. (1996). Discrepancies among mother, child, and teacher reports: Examining the contributions of maternal depression and anxiety. Journal of Abnormal Child Psychology, 24, 749-765.

Cairns, R. B., Gariépy, J. L., \& Kindermann, T. (1991). Identifying social clusters in natural settings. Unpublished manuscript, University of North Carolina, Chapel Hill.

Cairns, R., Xie, H., \& Leung, M. (1998). The popularity of friendship and the neglect of social networks: Toward a new balance. In W. M. Bukowski \& A. H. Cillessen (Eds.), Sociometry then and now: Building on six decades of measuring children's experiences with the peer group (pp. 25-53). San Francisco, CA: Jossey-Bass.

Callaghan, S., \& Joseph, S. (1995). Self-concept and peer victimization among schoolchildren. Personality and Individual Differences, 18, 161-163.

Chi, T. C., \& Hinshaw, S. P. (2002). Mother-child relationships of children with ADHD: The role of maternal depressive symptoms and depression-related distortions. Journal of Abnormal Child Psychology, 30, 387-400.

Chilcoat, H. D., \& Breslau, N. (1997). Does psychiatric history bias mothers' reports? An application of a new analytic approach. Journal of the American Academy of Child \& Adolescent Psychiatry, 36, 971-979.

Cillessen, A. H. N., \& Bellmore, A. D. (1999). Accuracy of social self-perceptions and peer competence in middle childhood. Merrill-Palmer Quarterly, 45, 650-676.

Clasen, D. R., \& Brown, B. B. (1985). The multidimensionality of peer pressure in adolescence. Journal of Youth and Adolescence, 14, 451-468.

Cohen, J. (1988). Statistical power analysis for the behavioral sciences (2nd ed.). Hillsdale, NJ: Lawrence Erlbaum Associates, Inc.

Cohen, J., \& Cohen, P. (1983). Applied multiple regression/correlation for the behavioral sciences (2nd ed.). Hillsdale, NJ: Lawrence Erlbaum Associates, Inc.

Cole, D. A., \& Carpentieri, S. (1990). Social status and the comorbidity of child depression and conduct disorder. Journal of Consulting and Clinical Psychology, 58, 748-757.

Cole, D. A., Martin, J. M., Peeke, L. G., Seroczynski, A. D., \& Hoffman, K. (1998). Are cognitive errors of underestimation predictive or reflective of depressive symptoms in children? A longitudinal study. Journal of Abnormal Psychology, 107, 481-496.

Colvin, C. R., Block, J., \& Funder, D. C. (1996). Psychometric truths in the absence of psychological meaning: A reply to Zuckerman and Knee. Journal of Personality and Social Psychology, 70, $1252-1255$.

Crick, N. R., \& Grotpeter, J. K. (1995). Relational aggression, gender, and social-psychological adjustment. Child Development, 66, 710-722.

Edelbrock, C. (1994). Assessing child psychopathology in developmental follow-up studies. In S. L. Friedman \& H. C. Haywood (Eds.), Developmental follow-up: Concepts, do- mains, and methods (pp. 183-196). San Diego, CA: Academic Press.

Edelbrock, C., Costello, A. J., Dulcan, M. K., Kalas, R., \& Conover, N. C. (1985). Age differences in the reliability of the psychiatric interview of the child. Child Development, 56, 265-275.

Edwards, J. R. (1994). The study of congruence in organizational behavior research: Critique and a proposed alternative. Organizational Behavior and Human Decision Processes, 58, 51-100.

Epkins, C. C. (1994). Peer ratings of depression, anxiety, and aggression in inpatient and elementary school children: Rating biases and influence of rater's self-reported depression, anxiety, and aggression. Journal of Abnormal Child Psychology, 22, 611-628.

Epkins, C. C. (1995). Peer ratings of internalizing and externalizing problems in inpatient and elementary school children: Correspondence with parallel child self-report and teacher ratings. Journal of Emotional and Behavioral Disorders, 3, 203-213.

Fergusson, D. M., Lynskey, M. T., \& Horwood, L. J. (1993). The effect of maternal depression on maternal ratings of child behavior. Journal of Abnormal Child Psychology, 21, 245-269.

Frick, P. J., \& Kamphaus, R. W. (2001). Behavior rating scales in the assessment of children's behavioral and emotional problems. In C. E. Walker \& M. C. Roberts (Eds.), Handbook of clinical child psychology (3rd ed., pp. 190-204). New York: Wiley.

Frick, P. J., Silverthorn, P., \& Evans, C. (1994). Assessment of childhood anxiety using structured interviews: Patterns of agreement among informants and association with maternal anxiety. Psychological Assessment, 6, 372-379.

Galen, B. R., \& Underwood, M. K. (1997). A developmental investigation of social aggression among children. Developmental Psychology, 33, 589-600.

Gotlib, I. H., \& Hammen, C. L. (1992). Psychological aspects of depression: Toward a cognitive-interpersonal integration. London: Wiley.

Graham, S., \& Juvonen, J. (1998). Self-blame and peer victimization in middle school: An attributional analysis. Developmental Psychology, 34, 587-599.

Grills, A. E., \& Ollendick, T. H. (2002). Peer victimization, global self-worth, and anxiety in middle school children. Journal of Clinical Child and Adolescent Psychology, 31, 59-68.

Hart, C. H., Yang, C., Nelson, D. A., Robinson, C. C., Jin, S., Wu, P., et al. (2001). Subtypes of aggression in Chinese and U.S. preschoolers: Sex and peer status linkages. Manuscript in preparation.

Hawker, D. S. (1997). Socioemotional maladjustment among victims of different forms of peer aggression. Unpublished doctoral dissertation, University of Keele, United Kingdom.

Hawker, D. S., \& Boulton, M. J. (2000). Twenty years' research on peer victimization and psychosocial maladjustment: A metaanalytic review of cross-sectional studies. Journal of Child Psychology and Psychiatry, 41, 441-455.

Holmbeck, G. N. (2002). Post-hoc probing of significant moderational and mediational effects in studies of pediatric populations. Journal of Pediatric Psychology, 27, 87-96.

Hughes, J. N., Cavell, T. A., \& Grossman, P. A. (1997). A positive view of self: Risk of protection for aggressive children? Development and Psychopathology, 9, 75-94.

Ingram, R. E. (1984). Toward an information-processing analysis of depression. Cognitive Therapy and Research, 8, 443-478.

Juvonen, J., Nishina, A., \& Graham, S. (2001). Self-views versus peer perceptions of victim status among early adolescents. In J. Juvonen \& S. Graham (Eds.), Peer harassment in school (pp. 105-124). New York: Guilford.

Kazdin, A. E. (1990). Assessment of childhood depression. In A. M. La Greca (Ed.), Through the eyes of the child: Obtaining selfreports from children and adolescents (pp. 189-233). Boston: Allyn \& Bacon.

Kovacs, M. (1981). Rating scales to assess depression in school-aged children. Acta Paedopsychiatria, 46, 305-315. 
Ladd, G. W., \& Kochenderfer-Ladd, B. (2002). Identifying victims of peer aggression from early to middle childhood: Analysis of cross-informant data for concordance, estimation of relational adjustment, prevalence of victimization, and characteristics of identified victims. Psychological Assessment, 14, 74-96.

Lopez, C. (1998, April). Peer victimization: Preliminary validation of a self-report measure for young adolescents. Paper presented at the Society for Research on Adolescence, San Diego, CA.

McGrath, E. P., \& Repetti, R. L. (2002). A longitudinal study of children's depressive symptoms, self-perceptions, and cognitive distortions about the self. Journal of Abnormal Psychology, $111,77-87$.

Najman, J. M., Williams, G. M., Nikles, J., Spence, S., Bor, W., O'Callaghan, M., et al. (2000). Mothers' mental illness and child behavior problems: Cause-effect association or observation bias? Journal of the American Academy of Child and Adolescent Psychiatry, 39, 592-602.

Nolen-Hoeksema, S., \& Girgus, J. S. (1994). The emergence of gender differences in depression during adolescence. Psychological Bulletin, 115, 424-443.

Olweus, D. (1978). Aggression in the schools: Bullies and whipping boys. Washington, DC: Hemisphere.

Österman, K., Björkqvist, K., Lagerspetz, K. M. J., Kaukianen, A., Huesmann, L. R., \& Fraczek, A. (1994). Peer and self-estimated aggression and victimization in 8-year-old children from five ethnic groups. Aggressive Behavior, 20, 411-428.

Panak, W. F., \& Garber, J. (1992). Role of aggression, rejection, and attributions in the prediction of depression in children. Development and Psychopathology, 4, 145-165.

Patterson, G. R. (1982). Coercive family process. Eugene, OR: Castalia.

Perry, D. G., Hodges, E. V. E., \& Egan, S. K. (2001). Determinants of chronic victimization by peers: A review and new model of family influence. In J. Juvonen \& S. Graham (Eds.), Peer harassment in school (pp. 73-104). New York: Guilford.

Perry, D. G., Kusel, S. J., \& Perry, L. C. (1988). Victims of peer aggression. Developmental Psychology, 24, 807-814.

Prinstein, M. J. (2003). Interpersonal factors: Peer relationships. In A. Spirito \& J. Overholser (Eds.), Evaluation and treatment of adolescent suicide attempters: From research to practice (pp. 91-213). New York: Academic Press.

Prinstein, M. J. (in press). Assessment of adolescents' preferenceand reputation-based popularity using sociometric experts. Social Development.

Prinstein, M. J., Boergers, J., Spirito, A., Little, T. D., \& Grapentine, W. L. (2000). Peer functioning, family dysfunction, and psychological symptoms in a risk factor model for adolescent inpatients' suicidal ideation severity. Journal of Clinical Child Psychology, 29, 392-405.

Prinstein, M. J., Boergers, J., \& Vernberg, E. M. (2001). Overt and relational aggression in adolescents: Social-psychological adjustment of aggressors and victims. Journal of Clinical Child Psychology, 30, 479-491.

Prinstein, M. J., Cheah, C. S. L., \& Schweder, A. E. (2003). Peer victimization, cue interpretation, and internalizing symptoms: Preliminary concurrent and longitudinal findings for children and adolescents. Manuscript submitted for publication.

Prinstein, M. J., \& Cillessen, A. H. N. (2003). Forms and functions of adolescent peer aggression associated with high levels of peer status. Merrill-Palmer Quarterly, 49, 310-342.

Richters, J. E. (1992). Depressed mothers as informants about their children: A critical review of the evidence for distortion. Psychological Bulletin, 112, 485-499.

Rigby, K., \& Slee, P. (1999). Suicidal ideation among adolescent school children, involvement in bully-victim problems, and perceived social support. Suicide and Life-Threatening Behavior, 29, 119-130.
Rogosa, D., Brandt, D., \& Zimowski, M. (1982). A growth curve approach to the measurement of change. Psychological Bulletin, 92, 726-748.

Rudolph, K. D., \& Clark, A. G. (2001). Conceptions of relationships in children with depressive and aggressive symptoms: Social-cognitive distortion or reality? Journal of Abnormal Child Psychology, 29, 41-56.

Rudolph, K. D., Hammen, C., \& Burge, D. (1994). Interpersonal functioning and depressive symptoms in childhood: Addressing the issues of specificity and comorbidity. Journal of Abnormal Child Psychology, 22, 355-371.

Saylor, C. F., Finch, A. J., Spirito, A., \& Bennett, B. (1984). The Children's Depression Inventory: A systematic evaluation of psychometric properties. Journal of Consulting and Clinical Psychology, 52, 955-967.

Schwartz, D., Dodge, K. A., Pettit, G. S., \& Bates, J. E. (1997). The early socialization of aggressive victims of bullying. Child Development, 68, 665-675.

Terry, R., Coie, J. D., Lochman, J., \& Cillessen, A. H. N. (1998). Sampling issues in sociometric assessment. Unpublished manuscript, Duke University, Durham, NC.

Treutler, C. M., \& Epkins, C. C. (2003). Are discrepancies among child, mother, and father reports on children's behavior related to parents' psychological symptoms and aspects of parent-child relationships? Journal of Abnormal Child Psychology, 31, 13-27.

Underwood, M. K., Galen, B. R., \& Paquette, J. A. (2001). Top ten challenges for understanding gender and aggression in children: Why can't we all just get along? Social Development, 10, 248-266.

Vernberg, E. M. (1990). Psychological adjustment and experience with peers during early adolescence: Reciprocal, incidental, or unidirectional relationships? Journal of Abnormal Child Psychology, 18, 187-198.

Vernberg, E. M., Fonagy, P., \& Twemlow, S. (2000). Preliminary report of the Topeka Peaceful Schools Project. Topeka, KS: Menninger Clinic.

Vernberg, E. M., Jacobs, A. K., \& Hershberger, S. L. (1999). Peer victimization and attitudes about violence during early adolescence. Journal of Clinical Child Psychology, 28, 386-395.

Xie, H., Swift, D. J., Cairns, B. D., \& Cairns, R. B. (2002). Aggressive behaviors in social interaction and developmental adaptation: A narrative analysis of interpersonal conflicts during early adolescence. Social Development, 11, 205-224.

Youngstrom, E., Izard, C., \& Ackerman, B. (1999). Dysphoria-related bias in maternal ratings of children. Journal of Consulting and Clinical Psychology, 67, 905-916.

Youngstrom, E., Loeber, R., \& Stouthamer-Loeber, M. (2000). Patterns and correlates of agreement between parent, teacher, and male adolescent ratings of externalizing and internalizing problems. Journal of Consulting and Clinical Psychology, 68, 1038-1050.

Zakriski, A. L., \& Coie, J. D. (1996). A comparison of aggressive-rejected children's interpretations of self-directed and other-directed rejection. Child Development, 67, 1048-1070.

Zakriski, A. L., Seifer, R., Sheldrick, R. C., Prinstein, M. J., Dickstein, S., \& Sameroff, A. J. (1999). Child-focused versus school-focused sociometrics: A challenge for the applied researcher. Journal of Applied Developmental Psychology, 20, 481-499.

Zuckerman, M., Gagne, M., Nafshi, I., Knee, C. R., \& Kieffer, S. C. (2002). Testing discrepancy effects: A critique, a suggestion, and an illustration. Behavior Research Methods, Instruments, and Computers, 34, 291-303.

Received June 5, 2003

Accepted October 28, 2003 